\title{
Non-psychogenic primary polydipsia in autoimmune chronic active hepatitis with severe hyperglobulinaemia
}

\author{
M V TOBIN AND A I MORRIS \\ From the Gastroenterology Unit, Royal Liverpool Hospital, Liverpool
}

SUMMARY The association of hyperglobulinaemia with renal tubular acidosis and nephrogenic diabetes insipidus is well established. A patient with marked hyperglobulinaemia due to autoimmune chronic active hepatitis is described who presented with severe polydipsia and polyuria but had entirely normal renal tubular function indicating a primary thirst disorder.

Renal tubular acidosis associated with diabetes insipidus is a recognised feature of autoimmune chronic active hepatitis and other hyperglobulinaemic states. ${ }^{12}$ Excessive thirst in these circumstances is appropriate and secondary to polyuria caused by renal tubular insensitivity to antidiuretic hormone (ADH). We describe a patient with autoimmune chronic active hepatitis and severe hyperglobulinaemia who presented with polydipsia and polyuria but had entirely normal renal tubular function.

\section{Case history}

A 36 year old housewife became aware of increasing thirst during the summer of 1985 . She initially attributed this to the warm weather but when her daily fluid intake reached approximately 6 litres, she sought medical advice and was referred for investigation.

She denied any motives for her excessive fluid intake other than extreme thirst. There was no previous history of renal disease and she was not taking any medication. Physical examination showed mild jaundice, hepatomegaly and spider naevi. Antinuclear and smooth muscle antibodies were positive and serum globulin was grossly raised at $86 \mathrm{~g} / \mathrm{l}$ (normal $<35 \mathrm{~g} / \mathrm{l}$ ), with IgG predominant at $55 \mathrm{~g} / \mathrm{l}$

Address for correspondence: Dr M V Tobin, University Department of Medicine, Hope Hospital, Salford M6 8HD.

Received for publication 9 October 1987. (normal $8-15 \mathrm{~g} / \mathrm{l}$ ). Liver histology confirmed the diagnosis of chronic active hepatitis.

The absence of renal tubular acidosis was shown by ammonium chloride loading during which a urine $\mathrm{pH}$ of 5.0 was achieved. She did not have aminoaciduria, glycosuria or hypercalciuria and serum calcium and electrolytes, including chloride and bicarbonate, were normal. Creatinine clearance was $105 \mathrm{ml} / \mathrm{min}$. During initial observation with unrestricted fluids she drank 5 litres and passed 4.5 litres of urine in 24 hours. She complained of thirst when serum and urine osmolalities were 282 and $168 \mathrm{mOsmol} / \mathrm{kg}$, respectively. Urine volume decreased and urine and plasma osmolalities responded appropriately after water deprivation for eight hours, effects which were not enhanced by desmopressin, $2 \mu \mathrm{g}$ intramuscularly (Figure) indicating normal hypothalamic and renal responses to fluid restriction consistent with primary polydipsia.

After treatment with prednisolone $45 \mathrm{mg}$ daily, her thirst remitted within two weeks. Serum globulin concentrations fell steadily, returning to normal within three months and she is presently asymptomatic with an average daily fluid intake of 1.6 litres and normal liver function.

\section{Discussion}

Polydipsia occurring in autoimmune diseases with hyperglobulinaemia is usually secondary to excessive renal water loss caused by distal tubular dysfunction.' 

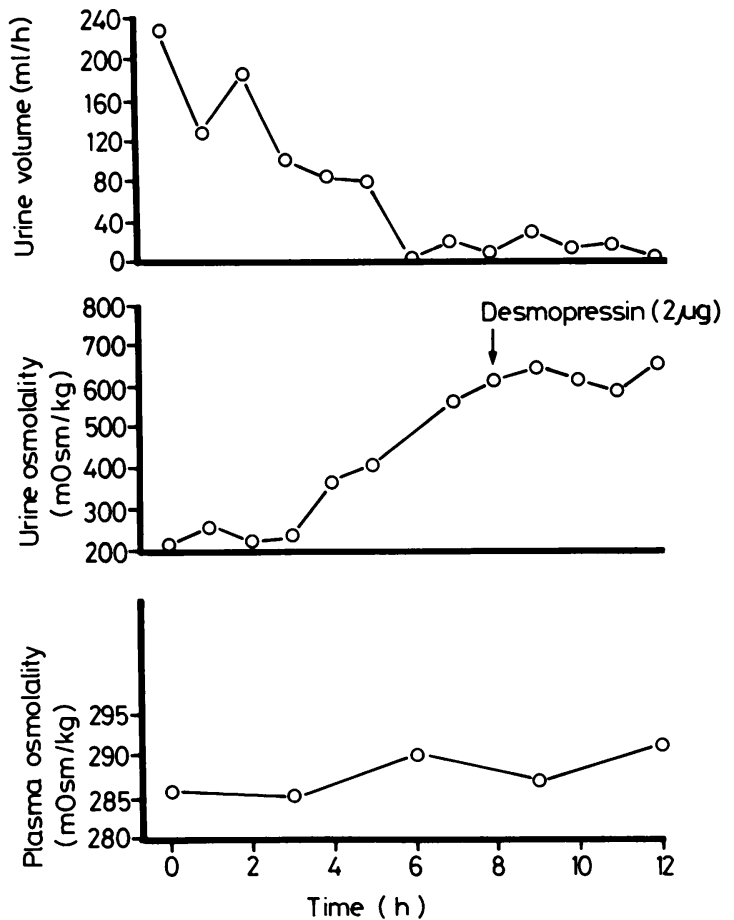

Figure Changes in urine volume and in urine and plasma osmolality during water deprivation.

Renal acidification and concentrating capacity are defective and the sensation of thirst is appropriate to induced changes in plasma osmolality and volume. Primary polydipsia, however, is a disorder of thirst in which an urge to drink persists in the absence of known physiological thirst stimuli. ${ }^{3}$ It is usually seen in association with cerebral damage ${ }^{4}$ and rarely in hypercalcaemia, ${ }^{5}$ severe potassium depletion ${ }^{5}$ and hyper-reninaemia. ${ }^{+67}$ It has also been reported in thyrotoxicosis $^{*}$ and in hypothalamic - pituitary sarcoidosis with normal ADH function. ${ }^{9}$ Psychogenic primary polydipsia usually occurs in middle aged women with a history of psychological disorder, is of sudden onset and fluctuates from day to day.$^{10}$ Thirst is seldom cited as a reason for the excessive intake..$^{10}$

That our patient had primary polydipsia is supported by the normal response to fluid deprivation and vasopressin and the low plasma osmolality at which she experienced thirst. It is impossible entirely to reject a psychogenic basis for her excessive intake. The rapid and permanent resolution of thirst following therapy for the underlying disease, however, suggests that as with other non-psychogenic forms of primary polydipsia,${ }^{89}$ a primary abnormality of the hypothalamic thirst mechanism, unrelated to osmotic or volume stimuli, is responsible.

\section{References}

1 Mason AMS, Golding PL. Hyperglobulinaemic renal tubular acidosis: a report of nine cases. $\mathrm{Br}$ Med J 1970; iii: $143-6$.

2 McCurdy DK, Cornwell GG, DePratti VJ. Hyperglobulinemic renal tubular acidosis. Ann Intern Med 1967; 67: 110-7.

3 Andersson B, Rundgren M. Thirst and its disorders. Ann Rev Med 1982; 33: 231-9.

4 Fitzsimons JT. The physiology of thirst and sodium appetite. Monogr Physiol Soc 1979, no. 35.

5 Fourman P, Leeson PM. Thirst and polyuria with a note on the effects of potassium deficiency and calcium excess. Lancet 1959; i: 268-71.

6 Rogers PW, Kurtzman NA. Renal failure, uncontrollable thirst and hyperreninemia. Cessation of thirst with bilateral nephrectomy. JAMA 1973; 225: 1236-8.

7 Sheth KJ, Tang TT, Blaedel ME, Good TA. Polydipsia, polyuria and hypertension associated with reninsecreting Wilms' tumour. J Pediatr 1978; 92: 921-4.

8 Evered DC, Hayter CJ, Surveyor I. Primary polydipsia in thyrotoxicosis. Metabolism 1972; 21: 393-403.

9 Stuart CA, Neelon FA, Lebovitz HE. Disordered control of thirst in hypothalamic-pituitary sarcoidosis. $N$ Engl J Med 1980; 303: 1078-82.

10 Barlow ED, DeWardener HE. Compulsive water drinking. $Q J$ Med 1959; 28: 235-58. 